\title{
Notas de um tradutor em 2012
}

RUBENS FIGUEIREDO

1

$\mathrm{E}$

NTENDI que a principal preocupação na tradução de livros como os de Tolstói deve ser a de preservar traços de linguagem e de pensamento que nos parecem estranhos, que não se enquadram nos hábitos ou padrões dominantes entre nós. Certas preferências de linguagem do original exprimem uma perspectiva, um ângulo a partir do qual se encara a vida e a sociedade. Uma parte crucial do significado desse tipo de obra reside justamente naquilo que soa discrepante do que esperamos de um "clássico da literatura”.

É preciso pelo menos deixar transparecer que, subjacente a essas preocupações linguísticas, há uma visão do mundo e da história diversa, radicada na sociedade onde aquela obra se formou. Isso contrasta com a forte pressão que hoje vigora para uma padronização generalizada. Também nesse ponto - a valorização da diversidade -, a tradução pode dar uma contribuição importante.

\section{2}

Quer dizer, o risco na tradução da literatura russa consiste em assimilarmos aqueles livros à perspectiva dominante em nossa sociedade. Isso compreende uma redução do alcance crítico e questionador das obras. A rigor, trata-se de uma tradução colonizadora, que toma a palavra do original.

Sem alguma noção crítica acerca do contexto em que a obra foi escrita, do que estava em jogo na época, da relação entre a literatura russa e a sociedade da época e, por outro lado, entre a literatura russa e o conceito de arte que era apresentado pela Europa como um valor universal, a tradução de livros como esses vai necessariamente perder uma parte vital de seu significado.

3

Esse tratamento assimilacionista da tradução das obras russas revela também um certo temor: o receio de ver, e mostrar, que existem outras formas possíveis, viáveis, de encarar e organizar a vida social, além daquela que vigora diante de nós e é tida como universal. Ou seja, o temor de ver e mostrar as fragilidades de fundo das formas sociais vigentes.

Tal receio, ou mais especificamente o objeto desse temor, é o motivo mesmo pelo qual aqueles livros nos atraem tanto e têm tanto a nos dizer.

4

No caso de Tolstói, há as repetições de palavras, de expressões e até de estruturas sintáticas inteiras. Há também os paralelismos múltiplos e cruzados, cinco ou seis concentrados em um único parágrafo. Uma espécie de retórica 
selvagem. Há o cuidado em dispor marcas linguísticas que distinguem as classes sociais, a origem cultural, o gênero e até a faixa etária dos personagens. Há a exploração de períodos longos que incluem construções com desvios sintáticos abruptos. Há a reprodução quase etnográfica da fala dos soldados e mujiques, que frisa seu caráter elíptico, conciso ao extremo. Se o tradutor tem consciência do que significam esses traços e de que nenhum deles é mera idiossincrasia ou virtuosismo de estilo, mas que estão associados aos questionamentos de fundo presentes no livro, ele tentará encontrar maneiras de preservá-los em português. Poderá distinguir o que é relevante do que é secundário.

\section{5}

Se o texto russo de Guerra e paz diz "guerra popular" e "força do povo", por que traduzir por "guerra patriótica" e "força da nação", como encontrei nas traduções para o inglês e o francês que consultei? Quando Tolstói usa a expressão guerra popular (naródnaia voiná), ele está se referindo às formas de resistência que a população rural russa passou a empregar contra as tropas de Napoleão. Queimaram milho, mataram os animais, destruíram silos, não deixaram nada para os invasores comerem. Não venderam comida para eles. Ou então se refere à ação militar de tropas irregulares dos milicianos, ou guerrilhas. A expressão "guerra patriótica" não se justifica. Então, por que tantas traduções em tantos idiomas insistiram em usar "guerra patriótica"? Porque a expressão "guerra popular" é muito agressiva, muito crítica. Sublinha a desigualdade social. Essa perspectiva não condiz com a noção de um "clássico da literatura universal", na qual Tolstói tinha de ser abarcado.

6

E no final do livro, Tolstói fala em "força do povo", e traduzem como "força da nação". Não é pouco. O sentido das palavras está no dicionário, mesmo assim o tradutor pode optar por interpretar. E de onde vem essa interpretação? Uma tradução depende muito da visão crítica que o tradutor tem da obra e do autor. Bem como da compreensão que ele tem da relação entre a obra e seu tempo, sua sociedade. Se essa visão crítica da obra, do autor, da relação da obra com a sociedade for frouxa, tímida, a tradução se torna passível de ser influenciada pelas noções dominantes. Isso afeta a tradução. E o sentido original vai se perder. O problema não é técnico. É um problema de entendimento crítico.

\section{7}

A tradução devia envolver uma troca, devia ser um veículo de intercâmbio cultural e de conhecimento recíproco. Mas hoje em dia não existe troca: as traduções quase que só são feitas do inglês para as outras línguas. No sentido inverso, a produção é estatisticamente nula. Hoje, a tradução é um processo unilateral. Isso denota uma relação de dominação e não de troca. A valorização do tradutor entre nós, infelizmente, parece ser, em grande parte, fruto da pressão de um processo de dominação, de que somos objeto. 
Há 22 anos traduzo literatura americana e inglesa contemporâneas e há dez anos, literatura russa do século XIX e início do século XX. O contraste não poderia ser mais chocante e elucidador.

De um lado - a literatura russa -, uma literatura que se integra às polêmicas em curso em seu tempo e em seu país; em que as obras debatem também umas com as outras tendo em vista as opções históricas abertas à sua sociedade; em que os autores se empenham com afinco em manter aberta uma via de acesso para a dinâmica social, com tudo o que essa comporta de explosivo e incerto. Nesse processo, praticamente tudo é submetido a um questionamento incisivo, a voltas e reviravoltas de pensamento e de posição, cujo acúmulo enriquece e revigora continuamente as obras. As opções artísticas de cada autor se referem às opções históricas do país e dessa forma as obras ganham o peso e a força que continuam a chamar a atenção, porque os processos históricos em curso e os padrões de relação social então em acelerada transformação podem, em medida nada desprezível, ser reconhecidos como os mesmos que hoje vigoram, mesmo que em outra roupagem.

De outro lado - a literatura inglesa e americana contemporânea -, uma literatura inserida no mercado, que postula o livro como um produto e uma mercadoria global; uma literatura em que qualquer questionamento concreto do regime de relações sociais vigente é neutralizado na fonte, pois isso significaria pôr em questão o próprio processo de produção desses livros, no qual uma obra é vendida para trinta países e classificada como de interesse mundial antes mesmo de ser concluída, lida e avaliada. Trata-se de uma literatura que mal tem consciência do processo em que está inserida e do teor propagandístico que assume. Nela, o alvo de algo parecido com visão crítica são sempre "os outros" (em especial sociedades que, de alguma forma, qualquer que seja, não se adaptaram ao capitalismo, ou mesmo a um certo tipo de capitalismo), mas nunca as relações sociais internas e as formas de poder em vigor em seus próprios países. No máximo, quanto a isso, se permitem queixas de teor moral. São obras beneficiárias de uma relação internacional desigual, que não questionam essa relação. Ao contrário, se empenham, direta ou indiretamente, em reforçá-la.

\section{9}

Você já viu aquelas caricaturas antigas sobre a África, em que os nativos carregam nos ombros uma espécie de andor com um inglês sentado em cima, com roupa safári e seu rifle de caça no colo? Pois é, eu quando traduzo esses livros americanos, ingleses, me sinto o cara que está embaixo do andor. Hoje em dia há um elemento colonialista nesse trabalho. Porque eu sou escritor também e, no tempo em que, talvez, poderia estar escrevendo, estou carregando os caras nas costas. Para que cacem leitores em nosso território. É claro que eu ganho para traduzir, sou um profissional, como dizemos para nos consolar. Recebo uma recompensa, é diferente daqueles africanos. Mas do ponto de vista de um 


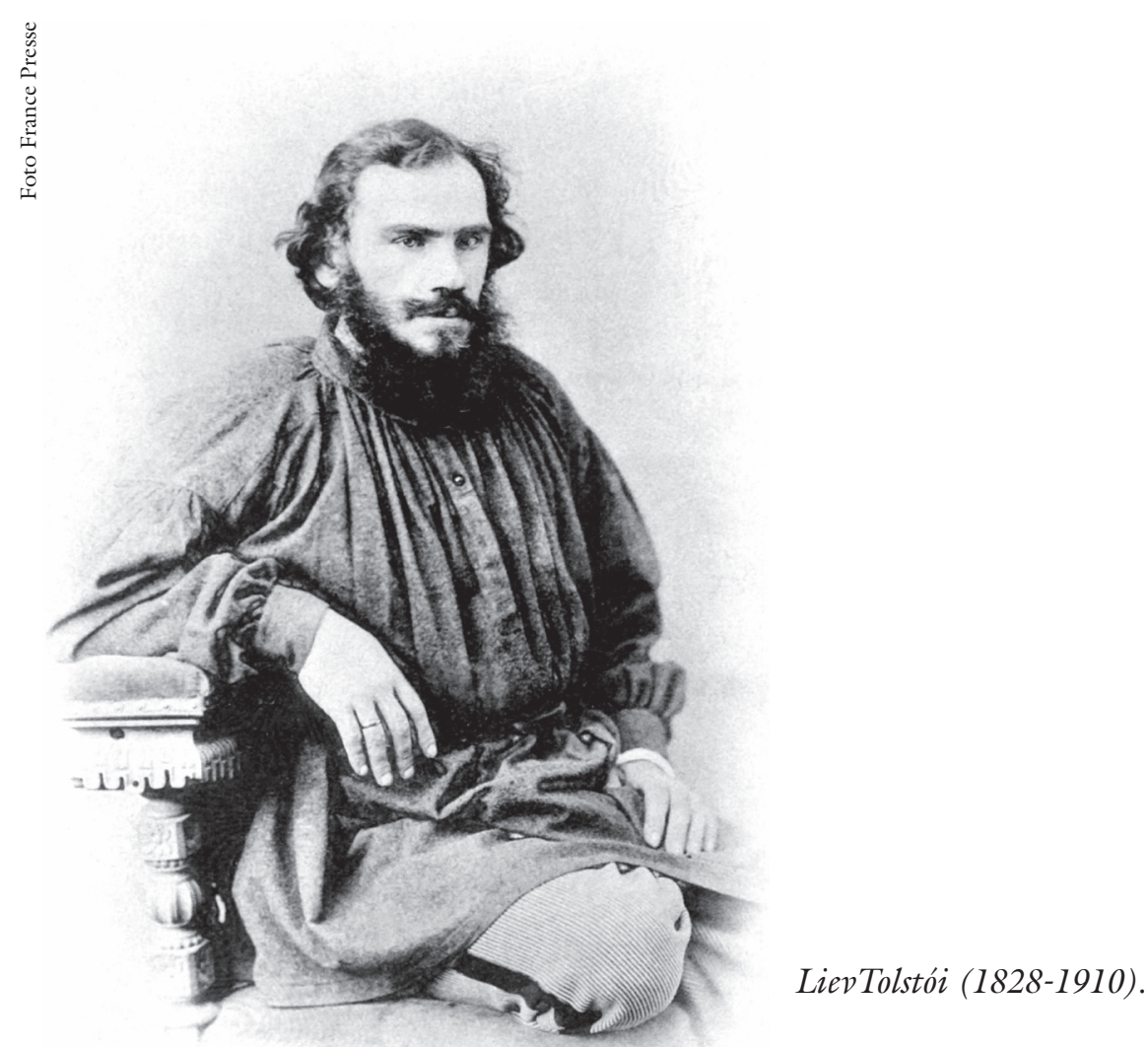

escritor, alguém que, bem ou mal, supõe que tem algo a dizer para seu país, para sua sociedade, e acaba sendo porta-voz forçado de outros, há algo de esquisito. Tem alguma coisa que não pode passar em branco.

\section{0}

Não me considero coautor das obras que traduzi. Mas seguramente sou o autor das traduções que fiz.

O trabalho de traduzir, no entanto, é muito semelhante ao de escrever um original. Quando você escreve, parte de impressões, ideias, sensações, emoções, sugestões, temores, enfim, que não se apresentam, em princípio, em linguagem verbal. E até resistem a ela. Você tem que transpor aquilo para a língua portuguesa escrita. É uma tradução. A rigor, a tradução, nesse sentido, é uma faculdade que todos usamos em nossa experiência cotidiana.

A tradução propriamente dita, aquilo que chamamos de tradução, é semelhante, só que você parte de um texto em outro idioma. Que é, em princípio, a consolidação de experiências e ideias de outra pessoa. Aí você tem que transpor aquilo também para o português escrito. Então há um ponto em que as duas coisas se cruzam - escrever a sua obra e escrever as traduções. A diferença é que as traduções vêm de experiências e ideias alheias, que na maioria dos casos não coincidem com as minhas e até se chocam com as minhas. 
A tradução permite uma leitura muito específica - dá margem a um distanciamento, desdobra nossa perspectiva. Por exemplo: é mais fácil eu perceber minhas limitações como escritor nas deficiências dos livros que traduzo do que relendo meus próprios textos.

RESUMO - O texto apresenta, em forma de notas, reflexões e observações de um tradutor a respeito de seu trabalho. Tanto no que se refere a questões de técnicas e procedimentos como no peso das relações sociais, nacionais e internacionais, em sua atividade, A partir da experiência de traduzir obras de autores russos do século XIX e início do século XX e também de autores americanos e ingleses contemporâneos, o texto tenta traçar um contraste e propor uma perspectiva crítica sobre a tradução e a literatura em nosso tempo.

PALAVRAS-CHAVE: Tradução, Tradutor, Literatura, Relações internacionais.

ABSTRACT - The essay presents, in the form of notes, the thoughts and observations of a translator about his work, with regard both to his techniques and procedures, and to the influence of national and international social relations on his activities. Grounded on his experience of translating the works of $19^{\text {th }}$-century and early $20^{\text {th }}$-century Russian authors, as well as those of contemporary American and English writers, this essay attempts to establish a contrast between, and propose a critical perspective of, translation and literature in our time.

KEYWORDS: Translation, Translator, Literature, International relations.

Rubens Figueiredo é formado em Letras pela Universidade Federal do Rio de Janeiro; é escritor, professor de Português e tradutor do inglês, do espanhol e do russo para o português. É autor dos romances Passageiro do fim do dia (2010) e Barco a seco (2001), e dos livros de contos Contos de Pedro (2006) e Livro dos lobos (2009), pela Companhia das Letras. Traduziu Guerra e paz, Ressurreição e Anna Kariênina, de Liev Tolstói, edições Cosac Naify. Vencedor do Prêmio de Tradução da Academia Brasileira de Letras, 2012. @ - rubensfigueiredo@gmail.com

Recebido em 14.8.2012 e aceito em 30.8.2012. 
